\title{
The Effect on KOSPI 200 Futures after Launching KOSPI 200 Option
}

\author{
J.P. TANG \\ Department of Finance, School of Economics, Xiamen University, Fujian, China
}

\begin{abstract}
In recent years, the change in Korea Exchange has aroused the world's concern for financial derivatives. In this paper, we analyzed the reason of the KOSPI 200 index option's success and the impact of launch of KOSPI 200 option. We used GARCH-GK $(1,1)$ model analyze the changes in volatility of KOSPI 200 index futures. We found that the launch of KOSPI 200 index option aggravates the liquidity and the volatility of KOSPI 200 index futures. The conclusion is important reference of China to launch $\mathrm{Hu}-\mathrm{Shen} 300$ index option and build the thorough risk prevention.
\end{abstract}

KEYWORLD: KOSPI 200 option; KOSPI 200 futures; liquidity; volatility; Hu-Shen 300 index

\section{BRIEF INTRODUCTION OF KOSPI 200 AND DERIVATIVES}

KOSPI 200 index, the short form of Korean Composite Stock Price Index, includes the first 200 largest and floating stocks issued in South Korean stock market. The index focus on the market value, and the value affects the index simultaneously. The index, came into operation from June 15th 1994, counted from the base period of January 3rd 1990, was developed as the target of exchange of stockindex futures and options. The Korea Stock Exchange (KSE) installed KOSPI 200 option on July 7, 1997. Since their first trading right before the dramatic economic crisis in Korea, the trading volume of KOSPI 200 option has been increasing at a rate of about $8 \%$ per month and now they are the most actively trades index in the world, surpassing the S\&P 100 and 500 options in the U.S. A daily of only 1,246 contracts were traded in July 1997 whereas trading had peaked at a level of nearly 83,000 contracts per day by December 1997 . In 2009 and 2010, the KOSPI 200 options were listed on the top of all exchange traded derivatives in the world with the trading volume of 2,920,990,655 and 3,525,898,562 transactions. KOSPI 200 futures were launched in Korea Stock Exchange on May 3, 1996. Since the Option Contract took effect in 1997, the volume of trade developed extremely rapid, as well as the popularity of the contract. Take the trading volume from 2003 to 2008 as an example, the volume increased 32 times.

\section{REASONS FOR RAPID DEVELOPMENT OF OPTIONS TRADING OF KOSPI 200}

The success of KOSPI 200 option market in Korea relative to other market has recently drawn significant attention from the world's investment community. One of the critical factors for the success of the KOSPI 200 options is the price volatility of the underlying asset. According to the opinions of Philippe Eme, mangier of Korean Fimat Group, small nominal value of the contract is the reason why KOSPI 200 caters to the stock market. The launch of KOSPI 200 Option in 1997 is a guarantee to KOSPI $200 \mathrm{Fu}-$ tures investing. The KOSPI 200 option adopt the operate mode of Europe options. Let's say multiplier is 100,000 won, premium is 0.01 points, the option price comes to 1000 won, nearly 8 Yuan, which is as low as the price of lottery ticket. Covenantlite attracts retail investor to participate in futures and options trading, which, at a very large extent, enlarges the number of investors' participation in financial derivatives trading. For example, the nominal value of Nikkei 225 index options and futures is nearly 15 times more than the one of option of KOSPI 200, meanwhile, the transaction cost of option of KOSPI 200 is one fifth of the cost of Nikkei index options. Mr. Philippe Eme said, "The desire and passion of trading among South Korean are unique." In South Korea, individual investors take major proportion of the investors in derivative market, whereas, in developed countries, the construction is totally different. In developed countries, institutional investors dominate the market, while individual investors and high leveraged investment take much less share in 
the market. According to the figures of KOFEX, in 2001, individual investors took a proportion of $50.6 \%$ of KOSPI 200 futures trading volume of investment, though it decreased to $44 \%$ in 2005 , they are still the main part of the market. Eme believes reduced commission is another reason that makes option trading of KOSPI 200 so popular. Broker receive 15 to 50 basis points of commission payments from traditional account, but only 3 basis points, that is, $\$ 0.03$, on online transaction.

\section{THE EFFECT OF KOSPI 200 FUTURES AFTER LAUNCHING KOSPI 200 OPTIONS}

According to the neoclassical finance theory, stock index futures could not play a role of hedging unless there exists a spot underlying asset in the portfolio. But in the theory, two derivatives with the same underlying could still build a hedge relationship. KOSPI 200 futures and KOSPI 200 option are based on the same underlying asset-KOSPI index. Thus, the same position of the two derivatives should be the same. While as the differences in cost and hedging function, KOSPI 200 futures and KOSPI 200 option have complementary effect.

\subsection{Promoting the Liquidity of KOSPI 200 Futures}

Several empirical studies report that asset liquidity has a significant impact on asset prices. For example, Amihud \& Mendelson (1986) [1], Kadlec \&
McConnell (1994) [2], and Brennan \& Subrahmanyam (1996)[3] report that stock prices are c.p. the lower, the lower stock liquidity is. For bond markets similar evidence is reported by Sarig \& Warga (1989)[4], Amihud \& Mendelson (1991)[5], and Kempf \& Uhrig-Homburg (2000)[6].

In the futures markets, there is no assurance that a liquid market may exist for offsetting a commodity contract at all times. Some future contracts and specific delivery months tend to have increasingly more trading activity and have higher liquidity than others. The most useful indicators of liquidity for these contracts are the trading volume and open interest.

Trading volume and open interest volume these two absolute values based on the depth of the market. The larger the depth, the more liquid is the security. Here, the relative measure value turnover rate $=$ trading volume/open interest volume could measure the liquidity objectively. Then we consider the liquidity ratio. Its calculation formula is liquidity ratio $=\mid \mathrm{lnPt}-$ $\operatorname{lnPt}-1 / /$ (open interest rate/trading volume). Liquidity ratio could comprehensive measure the liquidity. From table 2, we could easy read after launching KOSPI 200 option, in the short term, all the liquidity measures expect the mean of the price have a huge increase. While in the long term, the trade volume keeps constant, turnover ratio increases and liquidity ratio decreases. Therefore, we could say the launching of the KOSPI 200 option could boost the liquidity of KOSPI 200 futures.

Table 2: Liquidity Measures about KOSPI 200 futures

\begin{tabular}{|c|c|c|c|c|c|}
\hline Time & Trade Volume & Price (mean) & Trade Value & Turn-over Ratio & Liqui-dity Ration \\
\hline 960503970706 & $1,428,627$ & 80.7142 & $115,311,265.8$ & 0.7969 & 0.0335 \\
\hline 970707980706 & $8,495,499$ & 56.6720 & $481,457,035.3$ & 1.0523 & 0.1437 \\
\hline 980707991209 & $27,599,268$ & 75.7263 & $2,089,989,342.9$ & 1.7652 & 0.0152 \\
\hline 970707991209 & $36,094,776$ & 67.3936 & $2,432,555,642.8$ & 1.5224 & 0.0714 \\
\hline
\end{tabular}

\subsection{Volatility}

\subsubsection{Definition of GARCH Process}

An econometric term developed in 1982 by Robert F. Engle, an economist and 2003 winner of the Nobel Memorial Prize for Economics to describe an approach to estimate volatility in financial markets.

The GARCH framework proved to be very successful in predicting volatility changes. Empirically, a wide range of financial and economic phenomena exhibit the clustering of volatilities. As we have seen, GARCH models describe the time evolution of the average size of squared errors, that is, the evolution of the magnitude of uncertainty. Despite the empirical success of GARCH models, there is no real consensus on the economic reasons why uncertainty tends to cluster. That is why models tend to perform better in some periods and worse in other periods.

While GARCH model only put the close price into its model, we also want to consider the highest price, lowest price, open price and close price into our research model. Garman and Klass (1980)[7] propose several volatility estimators based on the knowledge of the opening, closing, highest and lowest prices. Like Parkinson (1980)[8], they assume the same diffusion process and propose their estimator:

$\hat{\sigma}_{G K}^{2}=0.511\left[\ln \left(\frac{H_{t}}{L_{t}}\right)\right]^{2}-0.19\left\{\ln \left(\frac{C_{t}}{O_{t}}\right)\left[\ln \left(H_{t}\right)+\ln \left(L_{t}\right)-\right.\right.$

$2 \operatorname{lnOt-2\operatorname {ln}HtOt\operatorname {ln}LtOt-0.383[\operatorname {ln}CtOt]2}$

$H_{t}$ is the highest price from time t- 1 to $\mathrm{t}$;

$L_{t}$ is the lowest price from time t-1 to t;

$o_{t}$ is the open price from time t-1 to t;

$C_{t}$ is the close price from time $\mathrm{t}-1$ to $\mathrm{t}$; 
In the case of continuous trading, the quote price would be changed a little.

$O_{t}=C_{t-1}, H_{t}=\max \left\{H_{t}, C_{t-1}\right\}, L_{t}=\max \left\{L_{t}, C_{t-1}\right\}$.

In this paper, our model that used to research the index futures' volatility change after launching index options is GARCH-GK. Its framework:

$$
\text { GARCH }-X: \quad \sigma_{t}^{2}=w+\beta \sigma_{t-1}^{2}+\alpha X_{t}^{2}
$$

where $w \geq 0, \beta>0, \alpha>0$ and $E\left[X_{t}^{2} \mid \Omega_{t-1}\right]=\sigma_{t}^{2}$.

$$
\begin{gathered}
R_{t}=\theta R_{t-1}+\varepsilon_{t} \\
\varepsilon_{t}=N\left(0, h_{t}{ }^{2}\right) \\
h_{t}{ }^{2}=\alpha_{0}+\alpha_{1} \varepsilon_{t-1}{ }^{2}+\beta_{1} h_{t-1}{ }^{2}+\theta \hat{\sigma}_{G K}^{2}+\gamma D
\end{gathered}
$$

$R_{t}$ - the logarithm rate of return of the index futures at time $\mathrm{t}$;

$R_{t-1}$ - the logarithm rate of return of the index futures at time $\mathrm{t}-1$;

$h_{t}$ - the conditional standard deviation at time $\mathrm{t}$;

$\varepsilon_{t}$-random standard deviation which follow $N\left(0, h_{t}{ }^{2}\right)$;

$\hat{\sigma}_{G K}$ - the standard deviation of Garman Klass statistics

$D$ - dummy variable.

\subsubsection{Data Source and Processing}

We select South Korea market as object to research the fluctuations of the KOSPI 200 index futures before and after the introduction of KOSPI 200 index option. As South Korea KOSPI 200 index option launched on July 7, 1997, and KOSPI200 index futures launched on May 3, 1996, we select the May 3, 1996 to December 9, 1999 as a range of sample interval. In order to obtain a continuous futures closing price data series we get the continuous futures contracts as follows: take the most recent month futures contract as a representative in the last month futures contract delivery month, select a futures contract, so that we get a continuous sequence of futures contracts. Use continuous futures contracts sequences of each trading day transaction data to generate a continuous sequence of options trading data.

Data used in the study sample consisted of: KOSPI 200 index for May 3, 1996 to December 9, 19991013 group index futures closing price data. In order to reduce imported error, we do logarithm processing to closing price series data. The logarithm daily yield equal the logarithm of closing price minus the logarithm of previous trading day's closing price $-R_{t}=100\left(\ln P_{t}-\ln P_{t-1}\right)$.

We describe the KOSPI200 index futures daily yield sequence in descriptive. From Table 3 we can see that the introduction of stock index options, KOSPI200 index futures in the short-term average yield decline, the long-term yields rise. Standard deviation of the KOSPI200 index futures in terms of long-term or short-term are far greater than the standard deviation of the pre-launch, for short-term stock index futures, reaction is more intense. The maximum and minimum values all appear in the long term after the introduction of stock index options in our study. Descriptive statistics show that introduction of KOSPI 200 index option increased the KOSPI 200 index futures volatility.

Table 3: Return of KOSPI200 futures descriptive statistics

\begin{tabular}{|c|c|c|c|c|}
\hline Time & Mean & Std & Skewness & Kurtosis \\
\hline 960503970706 & -0.0771 & 1.6513 & 0.3375 & 0.7969 \\
\hline 970707980706 & -0.2969 & 3.6487 & -0.1465 & 1.0523 \\
\hline 980707991209 & 0.0566 & 3.4436 & -0.0636 & 1.7652 \\
\hline 970707991209 & 0.0116 & 2.9646 & -0.0153 & 1.5224 \\
\hline
\end{tabular}

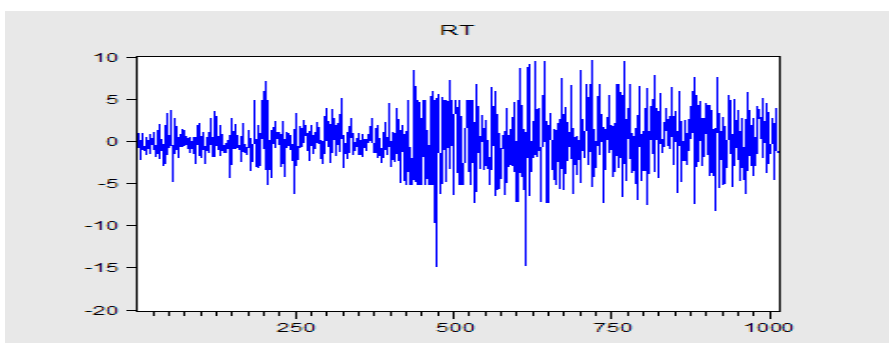

Figure 1: Distribution of KOSPI 200 futures daily return rate

From figure 1 we found that the volatility of KOSPI 200 futures daily return rate exist cluster effect. The volatility became larger after launching KOSPI 200 options.

\subsubsection{Result and Analysis}

(1) Testing

a. Stationary Testing

In our empirical study, log-transformation is first taken to standard the variable and then ADF test is applied to the series. As the absolute t-statistics is large and P-value is 0.0000 , the ADF test does reject the null hypothesis that the series is not stable.

Table 4: ADF Unit root Testing-Stationary Test

\begin{tabular}{|c|c|c|}
\hline & t-statistics & P-value \\
\hline $\begin{array}{c}\text { Augumented Dickey-Fuller } \\
\text { statistics }\end{array}$ & -29.49015 & 0.0000 \\
\hline
\end{tabular}

\section{b. ARCH Testing}

Both LM method and test of squares residual autocorrelation are ARCH effect test methods. Generate the new series $w t=r t$-mean $(r t)$, then generate the residual series $z=w t^{\wedge} 2$.

The coefficients of autocorrelation and partial autocorrelation in table 5 do not fall into twice the estimated standard deviation, and $\mathrm{P}$ values of the $\mathrm{Q}$ statistic were less than the confidence level of 0.05 , 99\% confidence level, then the result refuses the null hypothesis of return rate does not exists ARCH effect. That means KOSPI 200 futures yield exists ARCH effect. Using of GARCH-GK model to estimate is appropriate. 
Table 5: The autocorrelation of $\mathrm{z}-\mathrm{ARCH}$ Test

\begin{tabular}{|c|c|c|c|}
\hline AC & PAC & Q-Stat & Prob \\
\hline 0.132 & 0.132 & 17.558 & 0.000 \\
\hline 0.166 & 0.151 & 45.495 & 0.000 \\
\hline 0.150 & 0.116 & 68.294 & 0.000 \\
\hline 0.199 & 0.155 & 108.66 & 0.000 \\
\hline 0.186 & 0.125 & 143.81 & 0.000 \\
\hline 0.161 & 0.083 & 170.11 & 0.000 \\
\hline 0.139 & 0.052 & 189.84 & 0.000 \\
\hline 0.166 & 0.076 & 218.00 & 0.000 \\
\hline 0.096 & -0.007 & 227.32 & 0.000 \\
\hline 0.147 & 0.052 & 249.33 & 0.000 \\
\hline 0.115 & 0.022 & 262.84 & 0.000 \\
\hline 0.127 & 0.032 & 279.27 & 0.000 \\
\hline
\end{tabular}

\section{(2) GARCH-GK estimation}

In this paper, our model that used to research the index futures' volatility changes after launching index options is GARCH-GK. Its framework:

$$
G A R C H-X: \quad \sigma_{t}^{2}=w+\beta \sigma_{t-1}^{2}+\alpha X_{t}^{2}
$$

where $w \geq 0, \beta>0, \alpha>0$ and $E\left[X_{t}^{2} \mid \Omega_{t-1}\right]=\sigma_{t}^{2}$.

$$
\begin{gathered}
R_{t}=\theta R_{t-1}+\varepsilon_{t} \\
\varepsilon_{t}=N\left(0, h_{t}{ }^{2}\right) \\
h_{t}{ }^{2}=\alpha_{0}+\alpha_{1} \varepsilon_{t-1}{ }^{2}+\beta_{1}{h_{t-1}}^{2}+\theta \hat{\sigma}_{G K}^{2}+\gamma D
\end{gathered}
$$

$R_{t}$ - the logarithm rate of return of the index futures at time $\mathrm{t}$;

$R_{t-1}$ - the logarithm rate of return of the index futures at time $\mathrm{t}-1$;

$h_{t}$ - the conditional standard deviation at time t;

$\varepsilon_{t}$-random standard deviation which follow $N\left(0, h_{t}^{2}\right)$;

$\hat{\sigma}_{G K}$ - the standard deviation of Garman Klass statistics

$D$ - dummy variable.

Table 6: Output of return rate of KOSPI 200 futures with GARCH-GK $(1,1)$

\begin{tabular}{|c|c|c|c|c|}
\hline Variable & Parameter & St.d & z-Statistic & Prob \\
\hline Constant & 1.0201 & 0.1914 & 5.3292 & 0.0000 \\
\hline ARCH & 0.1080 & 0.0425 & 2.5416 & 0.0110 \\
\hline GARCH & 0.3864 & 0.0844 & 4.5814 & 0.0000 \\
\hline $\begin{array}{c}\text { Garman- } \\
\text { Klass }\end{array}$ & -0.2029 & 0.0190 & -10.6885 & 0.0000 \\
\hline Dummy & 2.0526 & 0.5365 & 3.8257 & 0.0001 \\
\hline
\end{tabular}

The parameter of the dummy variable is positive in table 6. The launching of KOSPI 200 option aggravates the volatility of KOSPI 200 futures.

\section{CONCLUSIONS}

The Korean stock market is an emerging market.
With its rational sets and low costs transaction, KOSPI 200 options have attracted large number of individual participants as well as foreign investors enter the options market. KOSPI 200 options not only active the derivative market and increase the liquidity of the market capitalization but also provide a good protection mechanism for the KOSPI $200 \mathrm{fu}-$ tures market. At the same time, its launching accelerates the volatility of the futures market, leading an increase in the risk of KOSPI 200 index futures market and helping set a more perfect market monitoring system.

In China, Hu-shen 300 stock index futures has launched for five years, after the stable development of Hu-shen 300 stock index futures, the Hu-shen 300 stock index options is introduced in this year, which will play a facilitative role in the liquidity of stock index futures market. In the early stages of launch of Hu-shen 300 stock index futures, because of the limitations of the legal system, the early market distribution was more institutional investors, less individual investors and foreign investors. With the future market becoming matures, it is necessary to extend the knowledge of financial derivative products, and gradually cultivate more individual investors and foreign investors. Finally, the launching of stock index options will result a larger volatility of stock index futures market, which means that the market risk increased, so improve laws and regulations of the financial derivatives market is essential.

\section{REFERENCES}

[1] Ahihud, Y. \& Mendelson H. 1986. Asset Pricing and the Bid-ask Spread. Journal of Financial Economics: 223-249.

[2] Kadlec G. B. \& McConnell J. J. 1994. The Effect of Market Segmentation and Illiquidity on Asset Prices: Evidence from Exchange Listings. The Journal of Finance: Vol. 49, 611-636.

[3] Brennan M. J. \& Subrahmanyam A. 1996. Market Microstructure and Asset Pricing: the Compensation for Illiquidity in Stock Returns. Journal of Financial Economic : 441-464

[4] Sarig O. \& Warga A. 1989. Some Empirical Estimates of the Risk Structure of Interest Rates. The Journal of Finance: Vol.44, 1351-1360

[5] Amihud Y. \& Mendelson H. 1991. Asset Prices and Financial Policy. Financial Analysts Journal: Vol. 47, 5666.

[6] Kempf A. \& Uhrig-Homburg M. 2000. Liquidity and its Impact on Bond Prices. Schmalenbach Business Review: Vol. 52, 26-44.

[7] Garman M. B. and Klass M.J. 1980. On the Estimation of Security Price Volatility from Historical Data. The Journal of Business: Vol. 53, 67-78.

[8] Parkinson M. 1980. The Extreme Value Method for Estimating the Variance of Rate of Return. The Journal of Business: Vol.53, 61-65. 